\title{
EDITORIAL
}

\section{Treating exercise oscillatory ventilation in heart failure: the detail that may matter}

\author{
Marco Guazzi
}

$\mathbf{0}$ ver the last 15 yrs, cardiologists have had to face a progressive recognition that abnormalities in the ventilatory response to exercise are relevant features of the heart failure syndrome [1]. Prior pathophysiology studies have defined the mechanistic role of the lung (impaired perfusion and increased minute ventilation $\left(V^{\prime} \mathrm{E}\right)$ ) [2] and of the periphery (increased chemo/metaboreflex sensitivity) [3] as determinants of the inefficient ventilatory response and early exercise termination.

A wealth of literature has indeed brought evidence that, whatever the predominant substrate, the increase in $V^{\prime} E$ relative to carbon dioxide production $\left(V^{\prime} \mathrm{CO}_{2}\right)$, primarily measured as the slope of this relationship, is a powerful indicator of disease severity $[1,4]$ that extends beyond peak oxygen uptake $\left(V^{\prime} \mathrm{O}_{2}\right)$, since its prognostic power is retained even when peak $V^{\prime} \mathrm{O}_{2}$ is near the normal range [5]. The consistency of these observations has substantially contributed to broadening the use of exercise gas exchange analysis for the clinical assessment and estimation of prognosis for the wide spectrum of heart failure populations [6].

As ventilation inefficiency has become an established matter of interest for heart failure specialists, further details have emerged as part of the picture, the most remarkable being exertional oscillatory ventilation (EOV) [7-12], a phenomenon originally described as anecdotal [13-15], and now considered a marker of disease severity even stronger than $V^{\prime} \mathrm{E} / V^{\prime} \mathrm{CO}_{2}$ slope itself [7-12]. EOV is a cyclic fluctuation of $V^{\prime} \mathrm{E}$ and expired gas kinetics occurring in approximately $20-30 \%$ of heart failure populations [4]. In contrast to the periodic oscillation observed in Cheyne-Stokes respiration and central sleep apnoea, the gradual increase and decrease in $V^{\prime} \mathrm{E}$ are not spaced by periods of apnoea. The source of this ventilatory abnormality is still controversial, but its clinical significance is clear [16].

Among the multiple criteria proposed for EOV definition $[7,8$, 10, 12], recent consensus statements [6] have adopted the simplest and perhaps most comprehensive one (oscillatory wave amplitude $\geqslant 15 \%$ of resting average $V^{\prime} E$ and cycle duration of $\geqslant 60 \%$ of exercise).

Heart Failure Unit, IRCCS Policlinico San Donato, University of Milan, Dept of Biomedical Sciences for Health, Milan, Italy.

CORRESPONDENCE: M. Guazzi, Heart Failure Unit, IRCCS Policlinico San Donato, University of Milan, Dept of Biomedical Sciences for Health, Piazza E. Malan 1, 20097 San Donato Milanese, Milan, Italy. E-mail: marco.guazzi@unimi.it
This definition actually covers a wide range of oscillatory patterns and may explain why, although initial evidence tightly linked this phenomenon to advanced heart failure [1315], a similar EOV prevalence has been confirmed in patients with mild heart failure [11] and in heart failure with preserved ejection fraction [10]. Notably, since risk prediction is strong even when $V^{\prime}$ E fluctuations are less severe, it may be inferred that the pathophysiology underlying this phenomenon is of special relevance, making EOV a contributor rather than a surrogate marker of the disease. Current views suggest that major pathways responsible for EOV include a demodulation of neural feedback due to augmented chemoreflex sensitivity [17] and a narrow difference between the eupnoeic carbon dioxide tension and apnoeic/hypoventilatory threshold [18]. The evidence for unstable neural control well supports the observation that EOV, and not $V^{\prime} \mathrm{E} / V^{\prime} \mathrm{CO}_{2}$ slope and peak $V^{\prime} \mathrm{O}_{2}$ predicts arrhythmic cardiac death [9]. Other proposed pathogenetic mechanisms include a prolonged circulatory time with failure of cardiac output to adequately increase and causing some delay in information transfer [14, 19]. In the most severe cases, EOV is also invariably related to increased pulmonary vascular resistances, right ventricular dysfunction [20] and pulmonary congestion [16, 21]. All these factors, alone or in combination, may contribute to the genesis of EOV; however, dissecting one from another is not an easy undertaking even though a number of theoretical models have been developed in an attempt to integrate the various clinical observations into a comprehensive mechanistic explanation [22].

In this issue of the European Respiratory Journal, ZUREK et al. [23] nicely demonstrate that EOV may be treatable and reversible. 3 months of aerobic training were quite effective in this respect, tempering the oscillatory pattern in a high proportion of patients $(71 \%)$ with stable congestive heart failure. Three previous reports investigated the effects of pharmacological interventions on EOV with an inodilator, milrinone [14], or a selective pulmonary vasodilator, sildenafil $[20,24]$. In each of these studies, some degree of EOV reversibility was documented at short- and longterm follow-up. Nonetheless, a strength of the present report is the demonstration of effectiveness of what, at least in theory, seems to be the most comprehensive intervention (aerobic training), to modulate at a multisystem level the pathogenetic mechanisms involved in EOV by "resetting" the central and peripheral control of $V^{\prime} E$ [25] and the haemodynamic perturbations responsible for an increased circulatory time [26]. As in the drug interventional studies, patients were optimally treated, $100 \%$ were receiving renin-angiotensin system inhibitors and $90 \% \beta$-blockers, suggesting that EOV is a phenomenon that may 
not be responsive to standard heart failure therapy, requiring a targeted ad hoc approach.

Modulation of EOV was accompanied by an improvement in the $V^{\prime} \mathrm{E} / V^{\prime} \mathrm{CO}_{2}$ slope as well, and an inverse correlation was found between changes in EOV amplitude and $V^{\prime} \mathrm{E} / V^{\prime} \mathrm{CO}_{2}$ steepness, which makes a lot of sense. However, $V^{\prime} \mathrm{E} / V^{\prime} \mathrm{CO}_{2}$ slope was not predictive of EOV reversibility, implying that the two markers, although sharing some putative mechanisms, can be dissociated in their determinants. These observations, along with the different clinical significance (higher prognostic prediction by EOV), argue against the simple conclusion that treating one component of abnormal $V^{\prime} \mathrm{E}$ may benefit the other and vice versa. Since EOV may or may not combine with a high $V^{\prime} \mathrm{E} / V^{\prime} \mathrm{CO}_{2}$ slope and the risk is additive [27], the practical implication is to ascertain that this subset of patients would really be successfully targeted.

Overall, the present findings add to the evidence in this area and raise some provocative questions regarding further directions. For example, how long will benefits persist after training cessation? Is a high-intensity aerobic training programme the add-on approach for nonresponder subjects? Is EOV reversal an on/off phenomenon or a progressive dose-response process? Most importantly, how might reverse changes really bear prognostic implications reflecting a true improvement in the natural history of the disease?

There are also some limitations to the study that warrant mentioning. The study was performed retrospectively and in an unblinded fashion. The lack of randomisation may be another relevant weakness for an interventional study that aims to clarify how to efficiently impact such an unfavourable clinical sign coupled with a complex pathophysiology.

These shortcomings, however, do not detract too much from the main study message, i.e. look at exercise ventilatory abnormalities as meaningful features of heart failure syndrome, place them in the right context and possibly treat appropriately.

As evaluating potential therapies for treating exercise $V^{\prime} \mathrm{E}$ abnormalities in heart failure is worth pursuing, several details remain to be investigated. Whether reversing EOV is a detail that may matter is a quest that awaits further details.

\section{STATEMENT OF INTEREST}

A statement of interest for M. Guazzi can be found at www.erj. ersjournals.com/site/misc/statements.xhtml

\section{REFERENCES}

1 Arena R, Myers J, Guazzi M. The clinical and research applications of aerobic capacity and ventilatory efficiency in heart failure: an evidence-based review. Heart Fail Rev 2008; 13: 245-269.

2 Sullivan MJ, Higginbotham MB, Cobb FR. Increased exercise ventilation in patients with chronic heart failure: intact ventilatory control despite hemodynamic and pulmonary abnormalities. Circulation 1988; 77: 552-559.

3 Piepoli M, Clark AL, Volterrani M, et al. Contribution of muscle afferents to the hemodynamic, autonomic, and ventilatory responses to exercise in patients with chronic heart failure: effects of physical training. Circulation 1996; 93: 940-952.

4 Sue DY. Excess ventilation during exercise and prognosis in chronic heart failure. Am J Respir Crit Care Med 2011; 183: 1302-1310.
5 Ponikowski P, Francis DP, Piepoli MF, et al. Enhanced ventilatory response to exercise in patients with chronic heart failure and preserved exercise tolerance: marker of abnormal cardiorespiratory reflex control and predictor of poor prognosis. Circulation 2001; 103: 967-972.

6 Balady GJ, Arena R, Sietsema K, et al. Clinician's Guide to cardiopulmonary exercise testing in adults: a scientific statement from the American Heart Association. Circulation 2010; 122: 191-225.

7 Leite JJ, Mansur AJ, de Freitas HF, et al. Periodic breathing during incremental exercise predicts mortality in patients with chronic heart failure evaluated for cardiac transplantation. I Am Coll Cardiol 2003; 41: 2175-2181.

8 Corrà U, Giordano A, Bosimini E, et al. Oscillatory ventilation during exercise in patients with chronic heart failure: clinical correlates and prognostic implications. Chest 2002; 121: 1572-1580.

9 Guazzi M, Raimondo R, Vicenzi M, et al. Exercise oscillatory ventilation may predict sudden cardiac death in heart failure patients. J Am Coll Cardiol 2007; 50: 299-308.

10 Guazzi M, Myers J, Peberdy MA, et al. Exercise oscillatory breathing in diastolic heart failure: prevalence and prognostic insights. Eur Heart J 2008; 29: 2751-2759.

11 Sun XG, Hansen JE, Beshai JF, et al. Oscillatory breathing and exercise gas exchange abnormalities prognosticate early mortality and morbidity in heart failure. J Am Coll Cardiol 2010; 55: 1814-1823.

12 Guazzi M, Boracchi P, Arena R, et al. Development of a cardiopulmonary exercise prognostic score for optimizing risk stratification in heart failure: the $(\mathrm{P}) \mathrm{e}(\mathrm{R}) \mathrm{i}(\mathrm{O})$ dic $(\mathrm{B})$ reathing during (E)xercise (PROBE) study. J Card Fail 2010; 16: 799-805.

13 Kremser CB, O'Toole MF, Leef AR. Oscillatory hyperventilation in severe congestive heart failure secondary to idiopathic cardiomyopathy or to ischaemic cardiomyopathy. Am J Cardiol 1987; 5: 900-905

14 Ribeiro JP, Knutzen A, Rocco MB, et al. Periodic breathing during exercise in severe heart failure: reversal with milrinone or cardiac transplantation. Chest 1987; 92: 555-556.

15 Ben-Dov I, Sietsema KE, Casaburi R, et al. Evidence that circulatory oscillations accompany ventilatory oscillations during exercise in patients with heart failure. Am Rev Respir Dis 1992; 145: 776-781.

16 Guazzi M, Boracchi P, Labate V, et al. Exercise oscillatory breathing and NT-proBNP levels in stable heart failure provide the strongest prediction of cardiac outcome when combining biomarkers with cardiopulmonary exercise testing. J Card Fail 2012; 18: 313-320.

17 Ponikowski P, Anker SD, Chua TP, et al. Oscillatory breathing patterns during wakefulness in patients with chronic heart failure: clinical implications and role of augmented peripheral chemosensitivity. Circulation 1999; 100: 2418-2424.

18 Xie A, Skatrud JB, Puleo DS, et al. Apnea-hypopnea threshold for $\mathrm{CO}_{2}$ in patients with congestive heart failure. Am J Respir Crit Care Med 2002; 165: 1245-1250.

19 Yajima T, Koike A, Sugimoto K, et al. Mechanism of periodic breathing in patients with cardiovascular disease. Chest 1994; 106: 142.

20 Murphy RM, Shah RV, Malhotra R, et al. Exercise oscillatory ventilation in systolic heart failure: an indicator of impaired hemodynamic response to exercise. Circulation 2011; 124: 1442-1451.

21 Olson TP, Frantz RP, Snyder EM, et al. Effects of acute changes in pulmonary wedge pressure on periodic breathing at rest in heart failure patients. Am Heart J 2007; 153: 104.

22 Francis DP, Wilson K, Davies LC, et al. Quantitative general theory for periodic breathing in chronic heart failure and its clinical implications. Circulation 2000; 102: 2214-2221.

23 Zurek M, Corrà U, Piepoli MF, et al. Exercise training reverses exertional oscillatory ventilation in heart failure patients. Eur Respir J 2012; 40: 1238-1244.

24 Guazzi M, Vicenzi M, Arena R. Phosphodiesterase 5 inhibition with sildenafil reverses exercise oscillatory breathing in chronic 
heart failure: a long-term cardiopulmonary exercise testing placebo-controlled study. Eur J Heart Fail 2012; 14: 82-90.

25 Stickland MK, Miller JD. The best medicine: exercise training normalizes chemosensitivity and sympathoexcitation in heart failure. J Appl Physiol 2008; 105: 779-781.

26 Erbs S, Höllriegel R, Linke A, et al. Exercise training in patients with advanced chronic heart failure (NYHA IIIb) promotes restoration of peripheral vasomotor function, induction of endogenous regeneration, and improvement of left ventricular function. Circ Heart Fail 2010; 3: 486-494.

27 Guazzi M, Arena R, Ascione A, et al. Exercise oscillatory breathing and increased ventilation to carbon dioxide production slope in heart failure: an unfavorable combination with high prognostic value. Am Heart J 2007; 153: 859-867. 